\title{
Effects of the regular intake of the probiotic Lactobacillus reuteri (DSM 17938) on respiratory and gastrointestinal infections in a workplace setting: a double-blind randomized placebo- controlled trial
}

\author{
Carsten Schröder $^{{ }^{*}}$, Stefanie Schmidt ${ }^{2}$, Edeltraut Garbe ${ }^{1}$, Joachim Röhmel ${ }^{3}$ and Klaus Giersiepen ${ }^{4}$
}

\begin{abstract}
Background: The regular intake of probiotics is alleged to help prevent or shorten the duration of common colds and gastrointestinal diseases. Previous clinical trials have shown protective effects in young children, while effects in adults have not yet been sufficiently investigated.

Methods: This study examines the effect of the regular intake of the probiotic Lactobacillus reuteri (DSM 17938) on the number of days of sick leave caused by respiratory and gastrointestinal diseases among male steelworkers. For this RCT, 242 male employees of ArcelorMittal Bremen were randomized. One hundred and twenty-one participants were assigned to take one chewable tablet containing at least $5 \times 10^{8}$ colony-forming units of L. reuteri per day over a period of 90 days. The 121 control participants were assigned to take a placebo. All participants were asked to keep a diary reporting days of sick leave and respiratory and gastrointestinal symptoms. Data of 159 participants were available for intention-to-treat analysis.
\end{abstract}

Results: Participants in the intervention group reported sick due to respiratory and gastrointestinal symptoms at an average of 2.24 of the 90 days under observation. In the control group, the average number of sick days was 2.02 $(p=0.53)$. Prevention of diarrhea was the only protective effect detected for the probiotic. Participants in the intervention group reported this symptom at an average of 0.60 , participants in the control group at 1.33 days $(p=0.01)$.

Conclusions: Our study could not show an effect of the intake of $L$. reuteri on the number of days of sick leave or on any of the symptoms of respiratory and gastrointestinal diseases with the exception of diarrhea.

The trial was registered in the German Clinical Trials Register on November 7, 2012 (www.germanctr.de; No.: DRKS00004430).

Keywords: Gastrointestinal diseases, Lactobacillus reuteri, Probiotics, RCT, Respiratory diseases, Sick leave

\footnotetext{
* Correspondence: c.schroeder@uni-bremen.de

'Department of Clinical Epidemiology at the Leibniz Institute for Prevention Research and Epidemiology_-BIPS GmbH, University of Bremen, Achterstraße 30, 28359 Bremen, Germany

Full list of author information is available at the end of the article
} 


\section{Background}

Work in the steel industry is related to stress factors which can negatively affect an employee's health. Alternating shifts, heavy physical work, and stressful environmental influences such as heat, noise, and dust lead to high rates of sick leave in this industry [1].

ArcelorMittal Bremen, part of the international steel group ArcelorMittal, observed a high and in recent years increasing rate of sick leave with a considerable portion caused by respiratory and gastrointestinal diseases (mainly common colds and diarrheal diseases).

Several studies have shown that the regular intake of a probiotic may prevent the occurrence or reduce the duration of respiratory and gastrointestinal diseases [2-6]. The Food and Agriculture Organization of the United Nations (FAO) and the World Health Organization (WHO) define probiotics as "Live microorganisms which when administered in adequate amounts confer a health benefit on the host" [7].

As of December 2013, we could only find one clinical trial investigating the effects of the intake of Lactobacillus reuteri on the rate of sick leave due to common colds and gastrointestinal diseases in adults (see Appendix). The randomized placebo-controlled trial was carried out at the multinational packaging company Tetra Pak in Sweden and showed a significant reduction of days of sick leave in the group randomized to the use of $L$. reuteri [8].

Numerous trials have demonstrated the safety of the probiotic $L$. reuteri. No side effects or adverse events were observed up to a daily dose of $10^{11}$ colony-forming units (CFUs) [9-14].

However, studies have not yet demonstrated the safety of the intake of some probiotic strains for people with preexisting conditions like diabetes, cancer, abscesses, pancreatitis, HIV, and organ transplants [14-18].

The present study examines whether the regular intake of $L$. reuteri is able to positively affect the rates of sick leave of male employees in the steel industry.

\section{Methods}

This double-blind randomized placebo-controlled parallel group design trial took place at ArcelorMittal Bremen. It was carried out from June 2012 to June 2013 (with the intervention period running from December 2012 to May 2013) and was initiated by ArcelorMittal due to high rates of sick leave in the steel production.

This study was conducted according to the guidelines laid down in the Declaration of Helsinki and all procedures involving human subjects were approved by the ethics committee of the Bremen State Medical Council. Written informed consent was obtained from all subjects.

Our target population was 671 male employees working at the blast furnace and the hot strip mill at the ArcelorMittal steel company in Bremen, comprising shift workers performing heavy physical work as well as employees without alternating shifts and mostly engaged in sedentary work. These employees were informed about the planned research project via posters, flyers, and informational lectures.

Because of the low proportion of female employees in the participating working areas (about 1.8\%), the study sample exclusively consists of men aged between 18 and 65 years. Persons with a history of diabetes, cancer, abscesses, pancreatitis, HIV, and organ transplants were excluded from the study due to the not yet verified harmlessness of some probiotic strains for patients with these preexisting conditions [14-18]. As shown in Figure 1, seven individuals had to be excluded.

Study participants were randomly assigned to the intervention or control group using a computer-generated list of random numbers. Participants in the intervention group were assigned to take one chewable tablet containing at least $5 \times 10^{8}$ colony-forming units of $L$. reuteri per day over a period of 90 days. Other ingredients of the tablets were isomalt, xylitol, palm oil, lemon-lime flavoring, and citric acid. Over the same period of time, participants in the control group were required to take one placebo tablet per day, consisting of the same ingredients as the verum tablets except for $L$. reuteri. Verum and placebo were provided free of charge in sealed vials labeled A and B by BioGaia, Sweden, without any conditions. The vials contained 30 tablets and were refilled if lost. No pill counts were made as trade union representatives of ArcelorMittal had objected to any control measures.

With the recruitment running from December 2012 to February 2013, volunteers who had signed informed consent were requested to fill out a questionnaire recording year and country of birth, body height, and weight as well

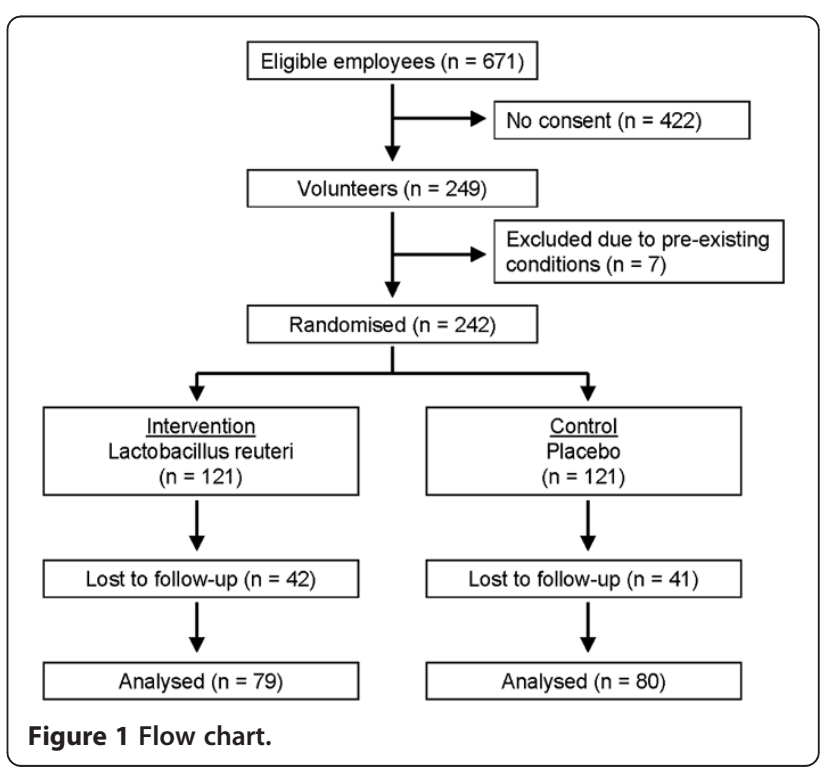


as working conditions and lifestyle habits. During the intervention period, running from December 2012 until May 2013, participants were asked to report in diary format respiratory and gastrointestinal symptoms such as cough, common cold, hoarseness, sore throat, earache, headache, fever, stomachache, diarrhea, and vomiting and their days of absence from work due to any of these symptoms by checking boxes in their prepared diaries once a day. The reported number of days absent from work was analyzed as the primary outcome, the symptoms as secondary outcomes.

Power calculations with an $\alpha$-error $=0.05, \beta=0.1$, and an anticipated difference in days absent from work between the two groups of 0.9 over 90 days had set the required number of individuals at 96 per group. $N_{\text {per Group }}=$ $2 \times[(1.96+1.28) \times 1.92 / 0.9]^{2}=96$.

With an expected loss to follow-up of $20 \%$, a minimum of 116 participants per group was required.

Data were analyzed using "SPSS 15.0" (www.ibm. com/software/de/analytics/spss). Data of participants who dropped out of the study before the end of the intervention period without revoking their consent were extrapolated to 90 days for the intention-to-treat analysis $(n=17)$. Chi-square test, $t$-test, and Fisher's exact test were used for the comparison of the sample characteristics in the intervention and control group. The primary and secondary outcomes were analyzed using the Wilcoxon-Mann-Whitney $U$-test as the data did not follow a normal distribution.

All statistical analyses are based on blinded data. The information whether the vials labeled A or B contained the active probiotic was only available to BioGaia and to an independent employee at Bremen University, who made that decision. The allocation seal was not broken until all analyses were completed.

All parts of the study (design, development of materials, enrollment of participants, data collection, analysis) were carried out by the authors of this paper.

\section{Results}

Two hundred and forty-nine of the 671 eligible employees agreed to participate in the study (37.1\%, Figure 1). Seven volunteers were excluded due to preexisting conditions so that 242 employees were randomized. Eighty-three participants did not return their study diaries and could therefore not be included in the statistical analysis. In total, the analysis is based on 159 of 242 randomized participants corresponding to a drop-out rate of $34.3 \%$.

The two groups were similar with regard to age, body weight, country of birth, working conditions, and most lifestyle habits (Table 1). The only discrepant finding was a higher consumption of probiotic foods like probiotic yogurts and yogurt drinks in the control group on a daily basis or several times a week $(p=0.04)$.

\section{Effect of the probiotic on days of sick leave}

Participants in the intervention group reported 176.9 days of sick leave due to respiratory and gastrointestinal symptoms per 7,110 days of observation (2.49\%), while participants in the control group missed 161.5 days of work for this reason per 7,200 days of observation (2.24\%) (Table 2). The average number of sick days per participant during the intervention period was 2.24 in the intervention and 2.02 in the control group ( $p=0.53)$.

The longest cumulative absence from work for a single participant was 30 days in the intervention group and 24 days in the control group. Approximately $65 \%$ of the study subjects in the intervention group and $70 \%$ in the control group reported zero days of sick leave due to respiratory and gastrointestinal symptoms during the intervention period.

The 28 participants in the intervention group with at least one day of sick leave due to respiratory and gastrointestinal symptoms reported sick on an average of 6.3 days. The 24 participants in the control group with at least one day of sick leave caused by the same symptoms reported sick on an average of 6.7 days $(p=0.71)$.

\section{Effect of the probiotic on symptoms of respiratory and gastrointestinal diseases}

One or more symptoms on at least one of the 90 intervention days were reported by $84.8 \%$ of the participants in the intervention group and by $87.5 \%$ of the participants in the control group ( $p=0.62$; Table 3$)$. Analysis by distinct symptoms was balanced in the study groups. The only significant difference was a protective effect observed for L. reuteri for diarrhea. Diarrhea occurred in $20.3 \%$ of the intervention group and in $37.5 \%$ of the control subjects $(p=0.02)$.

No differences were detected concerning the average number of days with symptoms during the intervention period (Table 4). Again, the only observed benefit was a lower incidence of diarrhea. On average, diarrhea was reported on 0.60 days for participants in the intervention group (1.33 days in the control group; $p=0.01$ ).

Almost all of the recorded symptoms occurred more frequently in individuals assigned to placebo. This trend can also be seen when adding up all the individual symptoms each participant reported over the 90 intervention days. On average, participants in the control group reported 42.5 out of a possible 900 individual symptoms during the 90 days of the intervention. Participants in the intervention group reported on average 32.67 symptoms $(p=0.25)$.

No harms or unintended effects were reported.

\section{Discussion}

This randomized controlled trial did not detect an effect of the probiotic L. reuteri on the number of days of sick 
Table 1 Characteristics of the study population

\begin{tabular}{|c|c|c|c|}
\hline & Intervention group $(n=121)$ & Control group $(n=121)$ & $p$-value ${ }^{a}$ \\
\hline \multicolumn{4}{|l|}{ Age: } \\
\hline Mean (SD) & 41.7 years $(9.9)$ & 41.7 years $(9.6)$ & 1.0 \\
\hline Minimum-maximum & $19-61$ & $19-58$ & \\
\hline$<30$ & 19 (15.7\%) & $17(14.0 \%)$ & 0.62 \\
\hline 30 to $<40$ & $30(24.8 \%)$ & $24(19.8 \%)$ & \\
\hline 40 to $<50$ & $42(34.7 \%)$ & $51(42.1 \%)$ & \\
\hline 50 to $<60$ & $29(24.0 \%)$ & $29(24.0 \%)$ & \\
\hline $60+$ & $1(0.8 \%)$ & $0(0.0 \%)$ & \\
\hline \multicolumn{4}{|l|}{ BMI: } \\
\hline Mean (SD) & $27.8(3.9)$ & $27.5(3.8)$ & $95 \% \mathrm{Cl},-0.7$ to $1.2, p=0.57$ \\
\hline Min-max & $18.4-40.2$ & $17.9-36.8$ & \\
\hline Underweight & $1(0.8 \%)$ & $1(0.8 \%)$ & 0.96 \\
\hline Normal & $29(24.0 \%)$ & $30(24.8 \%)$ & \\
\hline Overweight & $56(46.3 \%)$ & $57(47.1 \%)$ & \\
\hline Obesity & $35(28.9 \%)$ & $33(27.3 \%)$ & \\
\hline \multicolumn{4}{|l|}{ Country of birth: } \\
\hline Germany & $103(85.1 \%)$ & $98(81.0 \%)$ & 0.17 \\
\hline Turkey & $11(9.1 \%)$ & $8(6.6 \%)$ & \\
\hline Others & $7(5.8 \%)$ & $15(12.4 \%)$ & \\
\hline \multicolumn{4}{|l|}{ Work: } \\
\hline Shift work & $60(49.6 \%)$ & $66(54.5 \%)$ & 0.44 \\
\hline Part time & $2(1.7 \%)$ & $1(0.8 \%)$ & $1,0^{b}$ \\
\hline Mostly standing & $69(57.0 \%)$ & $72(59.5 \%)$ & 0.75 \\
\hline Mostly sedentary & $47(38.8 \%)$ & $45(37.2 \%)$ & \\
\hline \multicolumn{4}{|l|}{ Reported working exposures: } \\
\hline Noise & $69(57.0 \%)$ & $76(62.8 \%)$ & 0.36 \\
\hline Temperature fluctuations & $66(54.5 \%)$ & $76(62.8 \%)$ & 0.19 \\
\hline Heat & $42(34.7 \%)$ & $51(42.1 \%)$ & 0.28 \\
\hline Cold & 49 (40.5\%) & $52(43.0 \%)$ & 0.61 \\
\hline Dust & $65(53.7 \%)$ & $76(62.8 \%)$ & 0.15 \\
\hline Carbon dioxide & $24(19.8 \%)$ & $23(19.0 \%)$ & 0.82 \\
\hline Smoke & $22(18.2 \%)$ & $26(21.5 \%)$ & 0.63 \\
\hline Heavy lifting/carrying & $32(26.4 \%)$ & $31(25.6 \%)$ & 0.85 \\
\hline Mental stress & $74(61.2 \%)$ & $69(57.0 \%)$ & 0.51 \\
\hline \multicolumn{4}{|l|}{ Frequent lifestyle habits: } \\
\hline Smoking & $41(33.9 \%)$ & $39(32.2 \%)$ & 0.79 \\
\hline Alcohol consumption & $8(6.6 \%)$ & $7(5.8 \%)$ & 0.79 \\
\hline Physical activities & $43(35.5 \%)$ & $46(38.0 \%)$ & 0.69 \\
\hline Consumption of fruits and vegetables & $87(71.9 \%)$ & $99(81.8 \%)$ & 0.07 \\
\hline Consumption of probiotic foods & $4(3.3 \%)$ & $12(9.9 \%)$ & 0.04 \\
\hline Flu vaccination & $16(13.2 \%)$ & 12 (9.9\%) & 0.44 \\
\hline
\end{tabular}

${ }^{a} p$-values calculated using chi-square test or $t$-test.

${ }^{\mathrm{b}} p$-value calculated using Fisher's exact test. 
Table 2 Days of sick leave due to respiratory and gastrointestinal diseases within the 90 days of observation

\begin{tabular}{|c|c|c|}
\hline & $\begin{array}{l}\text { Intervention group } \\
(n=79)\end{array}$ & $\begin{array}{c}\text { Control group } \\
(n=80)\end{array}$ \\
\hline $\begin{array}{l}\text { Total number of days under } \\
\text { observation }\end{array}$ & 7,110 & 7,200 \\
\hline $\begin{array}{l}\text { Total number of days of sick } \\
\text { leave due to respiratory and } \\
\text { gastrointestinal diseases }\end{array}$ & 176.9 & 161.5 \\
\hline $\begin{array}{l}\text { Number of days of sick leave } \\
\text { as a percentage of the days } \\
\text { under observation }\end{array}$ & $2.49 \%$ & $2.24 \%$ \\
\hline \multicolumn{3}{|l|}{$\begin{array}{l}\text { Number of days of sick leave } \\
\text { per participant }\end{array}$} \\
\hline Mean & 2.24 & 2.02 \\
\hline Standard deviation & 4.74 & 4.28 \\
\hline Minimum & 0 & 0 \\
\hline Maximum & 30 & 24 \\
\hline $\begin{array}{l}\text { Number of participants with } \\
\text { at least one day of sick leave } \\
\text { during the intervention period }\end{array}$ & $28(35.4 \%)$ & $24(30.0 \%)$ \\
\hline \multicolumn{3}{|l|}{$\begin{array}{l}\text { Number of days of sick leave } \\
\text { for participants with at least } \\
\text { one day of sick leave }\end{array}$} \\
\hline Median & 5.0 & 5.0 \\
\hline Mean & 6.32 & 6.73 \\
\hline Standard deviation & 6.19 & 5.45 \\
\hline Minimum & 1 & 1 \\
\hline Maximum & 30 & 24 \\
\hline
\end{tabular}

leave due to respiratory and gastrointestinal diseases among male employees in the steel industry.

Our results stand in contrast to the findings of the slightly larger trial by Tubelius et al. 2005 [8], which took place at the Tetra Pak company in Sweden and which also investigated the effects of the regular intake of $L$. reuteri on sick leave caused by symptoms related to the respiratory and gastrointestinal tracts. In that study altogether, 262 volunteers were randomized to take either the probiotic $\left(10^{8} \mathrm{CFU}\right.$ per day) or a placebo over a period of 80 days. With a loss to follow-up of $31 \%, 181$ participants were included showing a strong protective effect for the intake of $L$. reuteri: Of the study subjects, $26.4 \%$ in the control group and $10.6 \%$ in the intervention group reported sick due to respiratory or gastrointestinal infections during the intervention period $(p<0.01)$. On average, participants in the control group reported sick on $0.9 \%$ of the study days, participants in the intervention group on $0.4 \%$ of the study days $(p<0.01)$.

The discrepant findings between the Swedish trial and ours may be due to the different workplace settings. Except for average age, sex, and whether or not the participants were shift workers, however, the publication of the
Table 3 Participants with symptoms on at least one day of the intervention period

\begin{tabular}{lccc}
\hline & $\begin{array}{c}\text { Intervention group } \\
(\boldsymbol{n}=\mathbf{7 9})\end{array}$ & $\begin{array}{c}\text { Control group } \\
(\boldsymbol{n}=\mathbf{8 0})\end{array}$ & $\boldsymbol{p}^{\text {-value }} \mathbf{a}^{\mathbf{a}}$ \\
\hline Cough & $50(63.3 \%)$ & $51(63.8 \%)$ & 0.95 \\
Common cold & $61(77.2 \%)$ & $57(71.3 \%)$ & 0.39 \\
Hoarseness & $35(44.3 \%)$ & $32(40.0 \%)$ & 0.58 \\
Sore throat & $38(48.1 \%)$ & $48(60.0 \%)$ & 0.13 \\
Earache & $12(15.2 \%)$ & $11(13.8 \%)$ & 0.80 \\
Headache & $47(59.5 \%)$ & $53(66.3 \%)$ & 0.38 \\
Fever & $18(22.8 \%)$ & $21(26.3 \%)$ & 0.61 \\
Stomachache & $19(24.1 \%)$ & $22(27.5 \%)$ & 0.62 \\
Diarrhea & $16(20.3 \%)$ & $30(37.5 \%)$ & 0.02 \\
Vomiting & $8(10.1 \%)$ & $2(2.5 \%)$ & $0.06^{\mathrm{b}}$ \\
Any symptom & $67(84.8 \%)$ & $70(87.5 \%)$ & 0.62 \\
\hline
\end{tabular}

${ }^{a} p$-values calculated using chi-square test or $t$-test.

${ }^{\mathrm{b}} p$-value calculated using Fisher's exact test.

Tetra Pak trial provides no further information about the participants' working conditions and lifestyle habits. No further information about the statistical analysis were provided. A comprehensive comparison of the two clinical trials was not possible due to this lack of information.

A per-protocol analysis in our study, which only included participants who reported having taken the chewable tablets on at least $90 \%$ of the intervention days $(n=144)$, did not show a significant effect of the probiotic on the number of sick days due to respiratory or gastrointestinal symptoms either. The average number of sick days per participant during the intervention period was 2.05 in the intervention and 2.01 in the control group $(p=0.81)$.

Our study was unable to detect an effect of $L$. reuteri on almost any of the symptoms covered by the questionnaire.

Table 4 Average number of days with symptoms during the intervention period

\begin{tabular}{lccc}
\hline & $\begin{array}{c}\text { Intervention group } \\
(\boldsymbol{n}=\mathbf{7 9})\end{array}$ & $\begin{array}{c}\text { Control group } \\
(\boldsymbol{n}=\mathbf{8 0})\end{array}$ & $\boldsymbol{p}^{\text {-value }} \mathbf{a}^{\mathbf{a}}$ \\
\hline Cough & 7.52 & 10.79 & 0.67 \\
Common cold & 10.38 & 13.81 & 0.51 \\
Hoarseness & 3.34 & 3.50 & 0.91 \\
Sore throat & 3.92 & 4.37 & 0.26 \\
Earache & 1.19 & 0.95 & 0.75 \\
Headache & 3.53 & 5.42 & 0.16 \\
Fever & 1.02 & 0.99 & 0.73 \\
Stomachache & 0.96 & 1.30 & 0.58 \\
Diarrhea & 0.60 & 1.33 & 0.01 \\
Vomiting & 0.21 & 0.04 & $\mathrm{~b}$ \\
Any symptom & 32.67 & 42.50 & 0.25 \\
\hline
\end{tabular}

${ }^{a} p$-values calculated using chi-square test or $t$-test.

${ }^{\text {b }}$ Statistical analysis not possible due to low case frequency. 
Only the results for diarrhea showed statistically significant preventive effects of regular intake. These findings comply with results of various other clinical trials, mostly examining infants and children, which already demonstrated this protective effect on the occurrence of diarrhea [3,19-26]. This could also be a chance finding due to multiple testing.

The described trend that almost all of the symptoms occurred at a lower rate in the intervention than in the control group suggests that the probiotic may have a protective effect even though the results were not statistically significant. The fact that statistical significance was not achieved may have been caused by the relatively low rate of returned study diaries.

The predefined power of the trial of $90 \%$ could not be achieved due to the high rate of missing data. An ex-post power calculation, based on the anticipated assumptions but considering the actual number of participants, revealed an actual power of $83.8 \%$.

Data of participants who did not complete the whole 90 days of the intervention were included in the intentionto-treat analysis. The daily statement of the participants in their study diaries whether they took the tablet or not was the only way to control intake and the only available information on which the per-protocol analysis could be based. Like all other collected data in this trial, the information about the intake of the probiotic is a statement by the study subjects that could not be verified.

No pill counts were conducted due to restrictions by ArcelorMittal's works committee. Pill counts would also have required greater commitment on the part of the volunteers and might thereby have discouraged employees from participating. In principle, it is possible to test compliance by measuring the concentration of $L$. reuteri in fecal specimens. That approach would have decreased the number of volunteers substantially and would not have been feasible given the available financial and human resources. Furthermore, it was not possible to validate information on frequency of sick leave by accessing the company's internal data due to data protection regulations.

The randomization was largely successful. As shown in Table 1, participants in the intervention and in the control group have similar characteristics. The only statistically significant difference observed between the two groups was the frequency of the consumption of probiotic foods. It can be assumed, however, that this difference did not result in a relevant decrease in the observed effect of the probiotic because the share of study subjects who reported having consumed probiotic foods regularly was less than $10 \%$ even in the control group. Furthermore, probiotic foods most often contain such small amounts of active microorganisms that their health effects are questionable.
Selection bias caused by healthy volunteers may have been present in our study but should have affected both intervention groups due to random allocation. Moreover, our results can only be generalized to companies in the steel industry and not to the general population due to the specific characteristics of the examined sample.

\section{Conclusions}

The probiotic L. reuteri did not affect the number of days of sick leave caused by respiratory and gastrointestinal diseases in our study. The results suggest that there might be a protective effect on the symptoms of the mentioned diseases even though only the effect on the occurrence of diarrhea reached statistical significance.

As our literature research via PubMed showed, the effects of probiotics on the development of respiratory and gastrointestinal diseases in adults have not yet been adequately investigated. Further scientific research is necessary to verify the results of the current and previous clinical trials. As the safety of $L$. reuteri has already been shown for much higher dosages, it might be appropriate for future studies to investigate the effects of a higher dose. In any case, these studies should include measurements of compliance in addition to information collected by diaries.

\section{Appendix}

Our search in the MEDLINE database restricted to "Clinical Trials" AND "Lactobacillus reuteri" yielded 89 hits. Of these 89 publications, published between April 1997 and August 2013, 78 investigated the effects of $L$. reuteri in humans (49 in adults, 29 in infants, children, and adolescents). These 78 publications mainly focused on oral health (33 studies) and gastrointestinal diseases like diarrhea (24 studies). Other studies investigated the safety of $L$. reuteri (six studies) and the effects on vaginal infections (nine studies), Helicobacter pylori infections (five studies), allergies (five studies), respiratory diseases (three studies), cholesterol level (two studies), rheumatism (one study), and obesity (one study).

Several clinical trials observed a correlation between lower incidences and shorter durations of gastrointestinal diseases and the regular intake of $L$. reuteri $[11,19-21,25,26]$.

\section{Competing interests}

The authors declare that they have no competing interests.

\section{Authors' contributions}

CS, SS, KG, and EG designed research; CS and SS conducted research; CS, SS, and JR performed statistical analysis; CS, SS, and KG wrote the paper; CS had primary responsibility for final content. All authors read and approved the final manuscript. 


\section{Acknowledgements}

The authors would like to thank ArcelorMittal Bremen GmbH, especially Dr. Andre Spahlinger, for the opportunity to execute the study and ArcelorMittal's employees for their participation.

We also thank BioGaia $A B$ for the provision of the study material. BioGaia $A B$ has not been involved in the funding, planning, implementation, or analysis of the trial.

\section{Financial support}

ArcelorMittal initiated the study and paid a temporary salary to CS and SS as students while working on this trial. KG, EG, and JR are university employees. There was no other external funding.

\section{Author details}

'Department of Clinical Epidemiology at the Leibniz Institute for Prevention Research and Epidemiology-BIPS GmbH, University of Bremen, Achterstraße 30, 28359 Bremen, Germany. ²Department of Human and Health Sciences, University of Bremen, Bibliothekstraße 1, 28359 Bremen, Germany. ${ }^{3}$ Leibniz Institute for Prevention Research and Epidemiology_BIPS GmbH, Achterstraße 30, 28359 Bremen, Germany. ${ }^{4}$ Centre for Social Policy Research (ZeS), University of Bremen, Mary Somerville Straße 5, 28359 Bremen, Germany.

Received: 26 June 2014 Accepted: 20 November 2014

Published: 21 January 2015

\section{References}

1. Redmann A, Rehbein I: Gesundheit am Arbeitsplatz. Eine Analyse von mehr als 100 Mitarbeiterbefragungen des WIdO 1995-98. In German) (Health at work. An analysis of more than 100 employee surveys by WIdO from 1995-98. Bonn: Wissenschaftliches Institut der AOK - WidO; 2000.

2. de Vrese M, Winkler P, Rautenberg P, Harder T, Noah C, Laue C, Ott S, Hampe J, Schreiber S, Heller K, Schrezenmeir J: Effect of Lactobacillus gasseri PA 16/8, Bifidobacterium longum SP 07/3, B. bifidum MF 20/5 on common cold episodes: a double blind, randomized, controlled trial. Clin Nutr 2005, 24:481-491.

3. Kekkonen RA, Lummela N, Karjalainen H, Latvala S, Tynkkynen S, Jarvenpaa S, Kautiainen H, Julkunen I, Vapaatalo H, Korpela R: Probiotic intervention has strain-specific anti-inflammatory effects in healthy adults. World J Gastroenterol 2008, 14:2029-2036.

4. Kang EJ, Kim SY, Hwang IH, Ji YJ: The effect of probiotics on prevention of common cold: a meta-analysis of randomized controlled trial studies. Korean J Fam Med 2013, 34:2-10.

5. Smith TJ, Rigassio-Radler D, Denmark R, Haley T, Touger-Decker R: Effect of Lactobacillus rhamnosus $\mathrm{LGG}^{\circledR}$ and Bifidobacterium animalis ssp. lactis BB- $12^{\circledast}$ on health-related quality of life in college students affected by upper respiratory infections. Br J Nutr 2013, 109:1999-2007.

6. King S, Glanville J, Sanders ME, Fitzgerald A, Varley D: Effectiveness of probiotics on the duration of illness in healthy children and adults who develop common acute respiratory infectious conditions: a systematic review and meta-analysis. Br J Nutr 2014, 112:41-54.

7. Food and Agriculture Organization of the United Nations \& World Health Organization: Guidelines for the Evaluation of Probiotics in Food. [ftp://ftp.fao.org/es/esn/food/wgreport2.pdf] (accessed November 2013).

8. Tubelius P, Stan V, Zachrisson A: Increasing work-place healthiness with probiotic Lactobacillus reuteri: a randomised, double-blind placebocontrolled study. Environ Health 2005, 4:25.

9. Wolf BW, Garleb KA, Ataya DG, Casass IA: Safety and tolerance of Lactobacillus reuteri in healthy adult male subjects. Microbial Ecology in Health \& Disease 1995, 8:41-50

10. Ruiz-Palacios G, Tuz F, Arteaga F, Guerrero ML, Dohnalek M, Hilty M: Tolerance and fecal colonization with Lactobacillus reuteri in children fed a beverage with a mixture of Lactobacillus spp. Pediatr Res 1996, 39:184.

11. Karvonen A, Casas I, Vesikari T: Safety and possible anti-diarrhoeal effect of the probiotic Lactobacillus reuteri after oral administration to neonates. Clin Nutr 2001, 20(suppl 3):63.

12. Weizman Z, Alsheikh A: Safety and tolerance of a probiotic formula in early infancy comparing two probiotic agents: a pilot study. J Am Coll Nutr 2006, 25:415-419.

13. Mangalat N, Liu Y, Fatheree NY, Ferris MJ, Van Arsdall MR, Chen Z, Rahbar $\mathrm{MH}$, Gleason WA, Norori J, Tran DQ, Rhoads JM: Safety and tolerability of
Lactobacillus reuteri DSM 17938 and effects on biomarkers in healthy adults: results from a randomized masked trial. PLoS One 2012, 7:e43910

14. Stein J, Dignass A: Wie sicher sind Probiotika? (German) (How safe are probiotics?). Pharmazie in unserer Zeit 2012, 41:146-148.

15. Cannon JP, Lee TA, Bolanos JT, Danziger LH: Pathogenic relevance of Lactobacillus: a retrospective review of over 200 cases. Eur J Clin Microbiol Infect Dis 2005, 24:31-40.

16. Boyle RJ, Robins-Browne RM, Tang ML: Probiotic use in clinical practice: what are the risks? Am J Clin Nutr 2006, 83:1256-1264

17. Arzneimittelinformation Berlin $\mathrm{GmbH}$ : Probiotika erhöhen Mortalität bei akuter Pankreatitis (German) (Probiotics increase mortality for patients with acute pancreatitis). [www.arznei-telegramm.de/blitz-pdf/b080214.pdf] (accessed November 2013).

18. Besselink MG, van Santvoort HC, Buskens E, Boermeester MA, van Goor H, Timmerman HM, Nieuwenhuijs VB, Bollen TL, van Ramshorst B, Witteman BJ, Rosman C, Ploeg RJ, Brink MA, Schaapherder AF, Dejong CH, Wahab PJ, van Laarhoven CJ, van der Harst E, van Eijck CH, Cuesta MA, Akkermans LM, Gooszen HG: Probiotic prophylaxis in predicted severe acute pancreatitis: a randomised, double-blind, placebo-controlled trial. Lancet 2008, 371:651-659.

19. Guerrero M, Dohnalek M, Newton P, Kuznetsova O, Murphy T, Calva J, Hilty $M$, Costigan T, Ruiz-Palacios G: Effect of probiotic-containing beverages on incidence of diarrhoea. In 1st World Congress of Pediatric Infectious Diseases. 1996. Abstract no. 610:45-2

20. Ruiz-Palacios G, Guerrero ML, Hilty M, Dohnalek M, Newton P, Calva JJ, Costigan T, Tuz F, Arteaga F: Feeding of a probiotic for the prevention of community-acquired diarrhea in young Mexican children. Pediatr Res 1996, 39:184.

21. Shornikova AV, Casas IA, Isolauri E, Mykkänen H, Vesikari T: Lactobacillus reuteri as a therapeutic agent in acute diarrhea in young children. J Pediatr Gastroenterol Nutr 1997, 24:399-404

22. Szajewska H, Mrukowicz JZ: Probiotics in the treatment and prevention of acute infectious diarrhea in infants and children: a systematic review of published randomized, double-blind, placebo-controlled trials. J Pediatr Gastroenterol Nutr 2001, 2(Suppl 33):17-25.

23. Eom TH, Oh EY, Kim YH, Lee HS, Yang PS, Kim DU, Kim JT, Lee BC: The therapeutic effect of Lactobacillus reuteri in acute diarrhea in infants and toddlers. Korean J Ped 2005, 48:986-989.

24. McFarland LV: Meta-analysis of probiotics for the prevention of antibiotic associated diarrhea and the treatment of clostridium difficile disease. Am J Gastroenterol 2006, 101:812-822.

25. Shornikova AV, Casas IA, Mykkänen H, Salo E, Vesikari T: Bacteriotherapy with Lactobacillus reuteri in rotavirus gastroenteritis. Pediatr Infect Dis 1997, 16:1103-1107.

26. Weizman Z, Asli G, Alsheikh A: Effect of a probiotic infant formula on infections in child care centres: comparison of two probiotic agents. Pediatrics 2005, 115:5-9.

\section{doi:10.1186/2055-0928-1-3}

Cite this article as: Schröder et al:: Effects of the regular intake of the probiotic Lactobacillus reuteri (DSM 17938) on respiratory and gastrointestinal infections in a workplace setting: a double-blind randomized placebo-controlled trial. BMC Nutrition 2015 1:3.

\section{Submit your next manuscript to BioMed Central and take full advantage of:}

- Convenient online submission

- Thorough peer review

- No space constraints or color figure charges

- Immediate publication on acceptance

- Inclusion in PubMed, CAS, Scopus and Google Scholar

- Research which is freely available for redistribution 